\title{
Water Content Monitoring in Water-in-Oil Emulsions Using a Piezoceramic Sensor
}

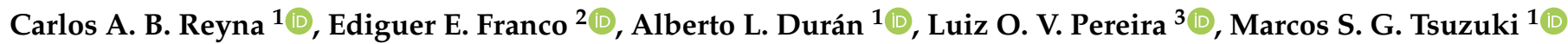 \\ and Flávio Buiochi ${ }^{1, *}$ (D) \\ 1 Department of Mechatronics and Mechanical Systems Engineering, Escola Politécnica da Universidade de \\ São Paulo, São Paulo 05508-030, Brazil; carlosburbano@usp.br (C.A.B.R.); duran@usp.br (A.L.D.); \\ mtsuzuki@usp.br (M.S.G.T.) \\ 2 Facultad de Ingeniería, Universidad Autónoma de Occidente, Cali 760030, Colombia; eefranco@uao.edu.co \\ 3 Research, Development and Innovation Petrobras S.A., Ilha do Fundão, Rio de Janeiro 21941-915, Brazil; \\ luizoctavio@petrobras.com.br \\ * Correspondence: fbuiochi@usp.br
}

Citation: Reyna, C.A.B.; Franco, E.E.; Durán, A.L.; Pereira, L.O.V.; Tsuzuki, M.S.G.; Buiochi, F. Water Content

Monitoring in Water-in-Oil Emulsions Using a Piezoceramic Sensor. Machines 2021, 9, 335. https://doi.org/10.3390/ machines 9120335

Academic Editor: Dan Zhang

Received: 17 October 2021

Accepted: 2 December 2021

Published: 6 December 2021

Publisher's Note: MDPI stays neutral with regard to jurisdictional claims in published maps and institutional affiliations.

\begin{abstract}
This work deals with a transmission-reception ultrasonic technique for the real-time estimation of the water content in water-in-crude oil emulsions. The working principle is the measurement of the propagation velocity, using two in-house manufactured transducers designed for water coupling, with a central frequency of about $3 \mathrm{MHz}$. Water-in-crude oil emulsions with a water volume concentration from $0 \%$ to $40 \%$ were generated by mechanical emulsification. Tests were carried out at three temperatures. The results showed that the propagation velocity is a sensitive parameter that is able to determine the water content, allowing for differentiating the concentrations of up to $40 \%$ of water. The main motivation is the development of techniques for non-invasive and real-time monitoring of the water content of emulsions in petrochemical processes.
\end{abstract}

Keywords: water-in-crude oil emulsion; water content; ultrasound; propagation velocity

\section{Introduction}

Petroleum is a mixture of organic compounds formed by the anaerobic decomposition of organic sediments in natural geological cavities or wells. The extraction techniques significantly modify its composition, adding an aqueous phase not miscible with the organic mixture and producing a complex emulsion [1]. Water is a contaminant in all oil derivatives, decreasing the quality of the resulting fuels [2], also implying higher pollution, which is a hindrance to the processes of transport, storage, and distillation. In addition, the water carries a wide variety of mineral solutes (sea salt, magnesium, and silicon, mainly) that damage pipes, valves, and pumps. The water is withdrawn from the raw oil, inducing coalescence, a process that consists of merging two or more droplets during contact to form a larger droplet $[3,4]$. This process may be enhanced by chemical substances. The final water content is a critical parameter in the subsequent petrochemical processing.

Characterization techniques for emulsions include electron and light microscopy, light and neutron scattering, electrical conductivity, and nuclear magnetic resonance [5,6]. Most of these techniques are only suitable for diluted and non-opaque emulsions, conditions not met by water-in-crude oil emulsions [6]. Other common methods for determining water content in crude oil, such as centrifugation [7], Karl Fisher's distillation, and grinding methods [8], require extracting a sample from the pipeline for further processing in a laboratory. These laboratory tests are time consuming and delay the processing and transportation of crude oil.

The real-time monitoring of water concentration before and after the coalescence process is of particular interest to the petrochemical industry [1]. Ultrasound can be useful for characterizing emulsions because it is robust, relatively inexpensive, easy to operate, 
allows characterizing opaque liquids and it provides in-line and real-time monitoring of emulsion stability evolution using a multi-backscattering sensor [9] and sand production monitoring using a wideband vibration sensor [10]. Ultrasound-based techniques have been used for characterizing liquids, such as edible oils, honey, polymer resins and motor oils [11-13], as well as for process monitoring, such as polymer and concrete curing [14,15]. As regards wave generation and reception methods, the literature reports the use of compact thick-film piezoelectric transducers [16], laser techniques for both the generation and reception of ultrasonic pulses [17] and conventional ultrasonic transducers [18].

In the case of multi-phase fluids, ultrasonic techniques have been used to characterize and to monitor some physical properties of emulsions, suspensions and slurries [19-21]. Other interesting works deal with the monitoring of a multiphase oil-water-gas flow directly in a pipe [18] and the detection of oily contaminants in water courses [22]. These works show the interest in the subject and the variety of possible approaches.

Water-in-crude oil emulsions showed a water concentration in a volume of $40 \%$ for droplet size distribution ranging from $0.4 \mu \mathrm{m}$ to $40 \mu \mathrm{m}$ [23] and a water concentration in a volume of up to $30 \%$ for droplet size distribution from $1 \mu \mathrm{m}$ to $10 \mu \mathrm{m}$ [1,5]. This characteristic, in addition to a high variation in their chemical composition, could lead to a dispersive medium with high attenuation. Under these conditions, the best approach must be the monitoring of an average acoustic parameter at a suitable operating frequency. Ultrasonic spectroscopy allows the determination of the distribution of droplet sizes and concentration by measuring the propagation velocity and attenuation spectra $[24,25]$. This is a well-established technique, useful in monomodal droplet size distribution, and restricted to diluted emulsions (volume fraction of the dispersed phase is less than 1\%) [26]. In a recent work [27], the authors used acoustic models and measured attenuation spectra to estimate the droplet size distribution in water-in-sunflower oil emulsions. They reported droplet size distributions of $0.4-5,0.4-8,0.4-15,0.4-12$ and $0.4-100 \mu \mathrm{m}$ for water volume fractions of $0.1,0.2,0.3,0.4$ and 0.5 , respectively. The droplet size distribution results of the ultrasonic spectroscopy for emulsions of moderate concentrations up to $20 \%$ were very close to the experimental data obtained by using laser diffraction.

The measurement of the propagation velocity of ultrasonic waves has been used to infer the physical properties of water-in-crude oil emulsions. In 2021, a novel multibackscattering sensor with a simple signal processing methodology, which allows the measurement of the propagation velocity, was proposed to monitor water-in-crude-oil emulsions [28]. The ultrasonic multiple-backscattering sensor consists of a 3.5-MHz transducer and a set of thin cylindrical scatterers located in the near field. The results from this experimental arrangement showed an almost linear behavior of the propagation velocity over a volumetric water concentration from $0 \%$ to $50 \%$. This interesting result was corroborated in the present work.

This paper presents an ultrasonic technique to estimate water concentration in waterin-crude oil emulsions. The working principle is the determination of the time of flight of ultrasonic waves between two custom-made transducers. The sensing device developed was initially tested with static samples to establish the measurement methodology. Other measurements were carried out with the sample being stirred by a laboratory mixer. This was done to maximize the droplet interaction, accelerating the coalescence process. The main motivation is the development of compact, inexpensive, and chemically and mechanically resistant devices, which could be attached to pipes or valves in the oil process lines for on-line and real-time monitoring.

\section{Theoretical Background}

Although emulsions are classified as continuous materials, they have local effects that generate a complex acoustic behavior. If the mean diameter of the dispersed phase droplets is smaller than the wavelength, the local acoustic phenomena converge to a wavefront traveling through the mixture with constant velocity. In this case, a simple acoustic propagation model relates the propagation velocity and the concentration, establishing 
that the total propagation time of an ultrasonic wave through a heterogeneous mixture is the sum of the times in each phase [29] (see Figure 1):

$$
t_{e}=t_{w}+t_{o}=\frac{X_{w}}{c_{w}}+\frac{X_{o}}{c_{o}}=\frac{X_{e}}{c_{e}}
$$

where $t$ is the propagation time, $X$ is the wave path length, $c$ is the propagation velocity and subscripts $e, w$ and $o$ refer to emulsion, water and oil, respectively. The relationship between propagation velocity $c$ in the emulsion and water volume fraction $\phi$ is:

$$
c_{e}=\frac{1}{\frac{\phi}{c_{w}}+\frac{1-\phi}{c_{0}}} .
$$

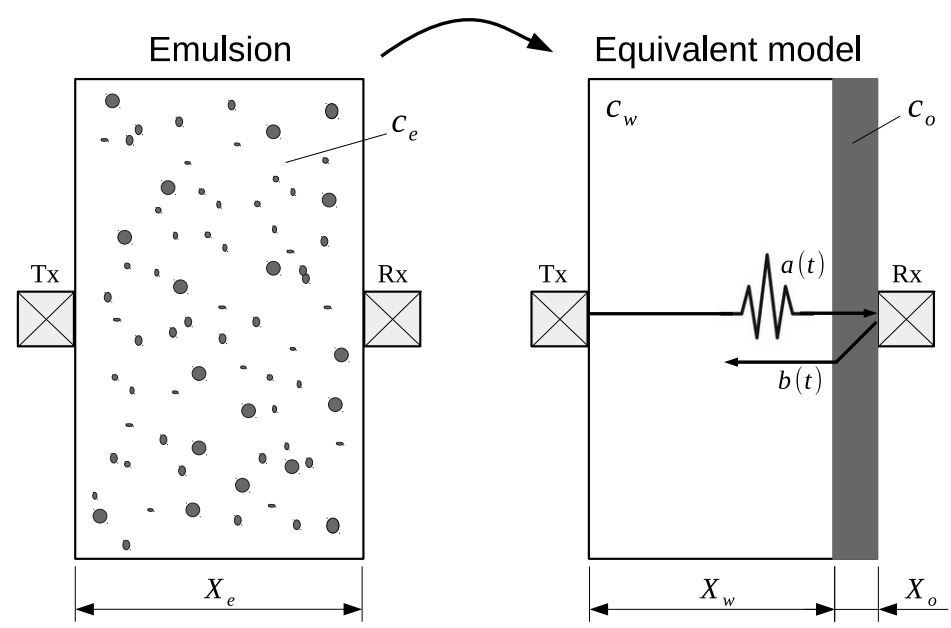

Figure 1. Measurement scheme, showing the mixture model for the propagation velocity in the emulsion (Urick's model) and the arrangement of the ultrasonic transducers and the transmitted $a(t)$ and reflected $b(t)$ signals.

Figure 1 also shows the ultrasonic transducer arrangement, composed of an emitter/receiver $(\mathrm{Tx})$ and a receiver $(\mathrm{Rx})$ and reflector. Transducer $\mathrm{Tx}$ is used in pulse-echo mode while transducer Rx operates as a receiver. The excitation of Tx generates wave $a(t)$ that propagates through the sample and reaches Rx. The part of the wave reflected from the $\mathrm{Rx}$ face generates signal $b(t)$, which returns to $\mathrm{Tx}$. This configuration allows the correlation of $a(t)$ and $b(t)$ with a shortest path $\left(X_{e}\right)$ between them and minimizes the insertion loss reflections by using other materials (steel or aluminum). As distance $X_{e}$ is known, time delay $t_{e}$ between signals $a(t)$ and $b(t)$ allows the determination of propagation velocity $c_{e}$ in the emulsion.

\section{Materials and Methods}

\subsection{Ultrasonic Probe}

The measurement probe, shown in Figure 2a, was manufactured using two square piezoelectric ceramics (10 mm sides and $0.36 \mathrm{~mm}$ thickness) of Pz37 (Ferroperm Piezoceramics A/S, Kvistgard, Denmark). The resulting transducers were tuned close to $3 \mathrm{MHz}$. Each probe transducer was manufactured in an ABS housing made in a $3 \mathrm{D}$ printer. The backing layer was made of epoxy resin (Araldite GY 279BR and Aradur HY 9BR, Huntsman, Brazil, in a ratio 10:1 by weight) mixed with alumina powder $(1 \mu \mathrm{m}$, Buehler, IL, USA) in a concentration of $30 \%$ by weight to increase the attenuation in the backing layer, avoiding the overlapping signals in reception and increasing the axial resolution. The matching layer was made with the same epoxy resin used in the backing layer, but without alumina powder, such that the matching was not complete. This way, the receptor can receive part of the energy but still reflect part of it to the emitter. There is a compromise 
here, because the pair of transducers can be used interchangeably (emitter or receptor). The matching layer thickness was approximately a quarter wavelength $(\lambda / 4 \cong 1.5 \mathrm{~mm})$. The transducer elements were aligned with a metallic spacer to ensure good parallelism. The distance between the transducers was $30 \mathrm{~mm}$, for acoustic echoes not to overlap when inserted into water. The propagation velocity in water is a well known property [30-34]. Then, the ultrasonic sensor was calibrated using distilled water as a reference substance. The calibration provides a more accurate value of the distance between transducers $\mathrm{Rx}$ and $\mathrm{Tx}$, which is required in the signal processing algorithm. Both transducers were tested in emission and in reception mode with slight differences in the measured delay.

(a)

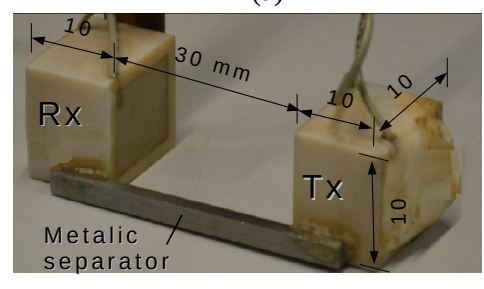

(c)

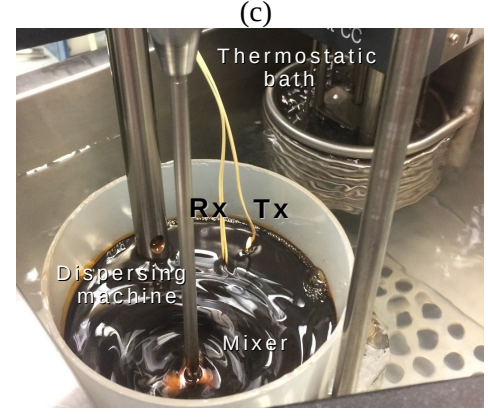

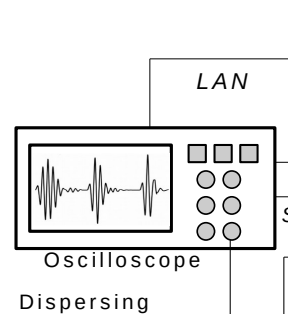

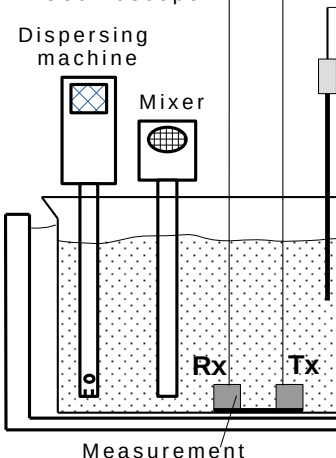

easurement (b)

Figure 2. Experimental setup: (a) Image of the in-house manufactured ultrasonic sensor (b) schematic representation and (c) image of the thermostatic bath with the emulsion under test.

\subsection{Experimental Setup}

Figure $2 b$ shows a schematic representation of the experimental setup. The emitter transducer (Tx), working in pulse-echo mode, was connected to an ultrasonic pulser/receiver (Olympus Panametrics model 5077-PR, Waltham, MA, USA), and the receiver transducer $(\mathrm{Rx})$ was directly connected to a channel of the oscilloscope. The digital oscilloscope (Agilent Technologies, model 5042, Santa Clara, CA, USA) was used to digitize the ultrasonic signals. The sample temperature was measured using a digital thermometer (DeltaOHM, model HD2107.2, Caselle di Selvazzano (PD), Italy). Both the oscilloscope and the digital thermometer were connected to a desktop computer allowing the simultaneous acquisition and storage of the ultrasonic signals and temperature via LAN network.

The temperature of the experiment was controlled by a thermostatic bath (Huber, CC-106A) with an accuracy of $0.1^{\circ} \mathrm{C}$. The emulsion was stored in an $800-\mathrm{mL}$ beaker partially immersed in the thermostatic bath. The ultrasonic sensor and the thermometer were inserted into the beaker. For homogenizing the emulsion, a dispersing machine (IKA Labortechnick, model T25, Staufen, Germany) was used at $8600 \mathrm{rpm}$. In addition, a 200-rpm mixer (Fisatom, model 711, São Paulo—SP, Brazil) was used to agitate the sample when measurements with moving fluid were desired. The mixer and emulsifier blades were completely inserted in the fluid to reduce the effect of air bubbles. Figure $2 \mathrm{c}$ shows an image of the experiment in the thermostatic bath. The sample can be seen spinning by the action of the mixer.

Figure 3 shows the waveforms of the ultrasonic pulses received by both the $\mathrm{Rx}$ and $\mathrm{Tx}$ transducers in pure water. The signal received by Tx has a different waveform and has a lower amplitude when compared to the signal received by Rx. The lower amplitude can be attributed to the energy loss inside transducer $\mathrm{Rx}$, which is a good receiver. Reverberation 
inside the transducer layers results in a set of signals that are added to produce the distorted waveform reflected by $\mathrm{Rx}$ and received by $\mathrm{Tx}$.

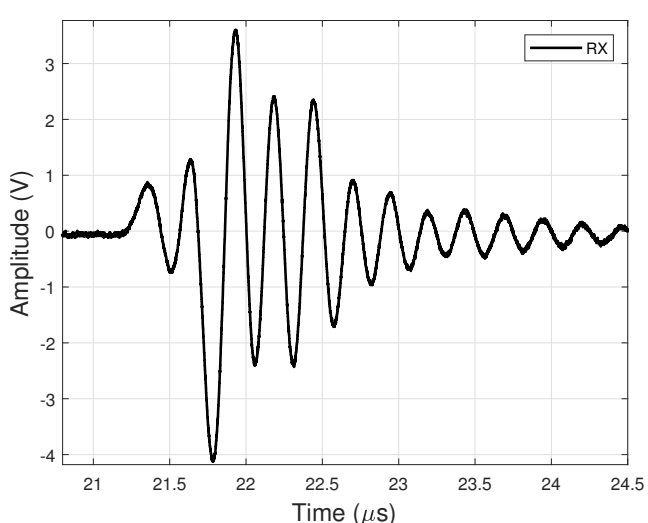

(a)

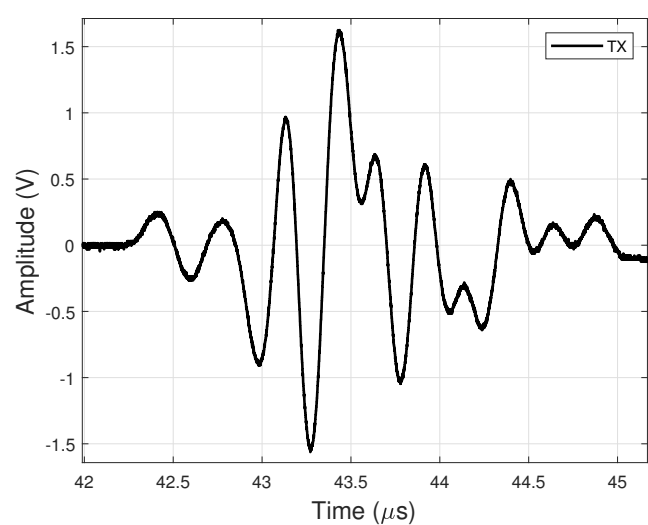

(b)

Figure 3. Signals obtained from transducers with water as the propagation medium: (a) Rx and (b) Tx.

Salt-water mixtures of different concentrations were used to test the measurement setup. The tests were carried out at $25{ }^{\circ} \mathrm{C}$ and the results were compared with others reported in the literature [30]. In the experiment, successive concentrations were obtained by adding $5 \mathrm{~g}$ of salt to a solution previously prepared. It started with $300 \mathrm{~g}$ of water and ended by achieving a salt concentration of $18.9 \%$ by weight. The solutions for each concentration were mixed for $150 \mathrm{~s}$ to completely dissolve the salt. At rest, ultrasonic signals were acquired to determine the propagation velocity of each solution. This procedure was repeated three times, and the averages and standard deviations of the propagation velocities were obtained.

\subsection{Experimental Procedure}

In petrochemical processes, measurements are required under flow conditions. The flow can affect the path of the acoustic waves, distorting the recorded signals. Experiments carried out at rest and with stirring allow comparison of the stability of the measurements obtained in these conditions. In this work, the flow condition was simulated by a stirring impeller (mixer) with three blades of radius $30 \mathrm{~mm}$ placed inside a beaker of diameter of $150 \mathrm{~mm}$. The angular velocity of the mixer was $200 \mathrm{rpm}$, a relatively low value to reduce the probability of cavitation in the sample, which could lead to the evaporation of the most volatile compounds in the crude oil.

The first experimental procedure used to test the emulsions started by pouring $300 \mathrm{~mL}$ of crude oil (30.5 API, well LL83, Mangaratiba, Petrobras, Brazil) into a beaker partially immersed in the thermal bath. The amount of water required for the desired concentration was added to the beaker. The dispersing machine $(8600 \mathrm{rpm})$ was turned on for $80 \mathrm{~s}$. Then, the mixture was left to stand for $40 \mathrm{~s}$ to minimize the effect of the heat and most air bubbles generated by the dispersing machine. The ultrasonic sensor was placed on the bottom of the beaker. Finally, 310 acquisitions, considering ultrasonic signals and temperature data, were taken during approximately $160 \mathrm{~min}$. The measurement process was carried out for three water volume fractions $(\phi=0.12,0.21,0.29)$ at $25^{\circ} \mathrm{C}$. All these measurements were repeated with the mixer turned on at $200 \mathrm{rpm}$.

For the concentration of $\phi=0.29$, the experiments were repeated with the emulsion samples at rest and in motion with the probe positioned close to the top surface of the emulsion ( $65 \mathrm{~mm}$ from the bottom of the beaker, Figure $2 \mathrm{~b}$ ). For the signals to be acquired, the mixer was turned off for static measurements in the sample and turned on for moving measurements in the same sample. 
To test a greater amount of concentration, a second experimental procedure was carried out. The measurements of water-in-crude oil emulsion were performed in the range of water volume fraction from 0 to 0.4 and three different temperatures $(20,25$ and $30{ }^{\circ} \mathrm{C}$ ). Each measurement was made after adding water to a previously prepared emulsion and turning on the dispersing machine for $80 \mathrm{~s}$, obtaining a new concentration. The emulsification process of the samples, followed by a rest period, was the same as the first experimental procedure described above, but in this case, only 30 ultrasonic signals were acquired during $110 \mathrm{~s}$. The measurements were repeated with the mixer turned on at $200 \mathrm{rpm}$. For each temperature, two samples were used for static acquisitions. After that, for each of the same three temperatures, two samples were used for dynamic acquisitions (mixer turned on at $200 \mathrm{rpm}$ ).

\section{Results and Discussion}

In Figure 4, the propagation velocities measured for salt-water mixtures were plotted as a function of the salt concentration and were compared with the theoretical velocity curve [35]. The measurements obtained by the ultrasonic sensor are in good agreement with the values in the literature [30] and the standard deviation is small. The linear behavior of the propagation velocity as a function of salt content was confirmed. However, there is a difference in the slope, although the maximum deviation between the theoretical and experimental cases is $0.6 \%$ at the highest concentration ( $19 \%$ by weight). These results show the measurement technique has good agreement in the case of solutions.

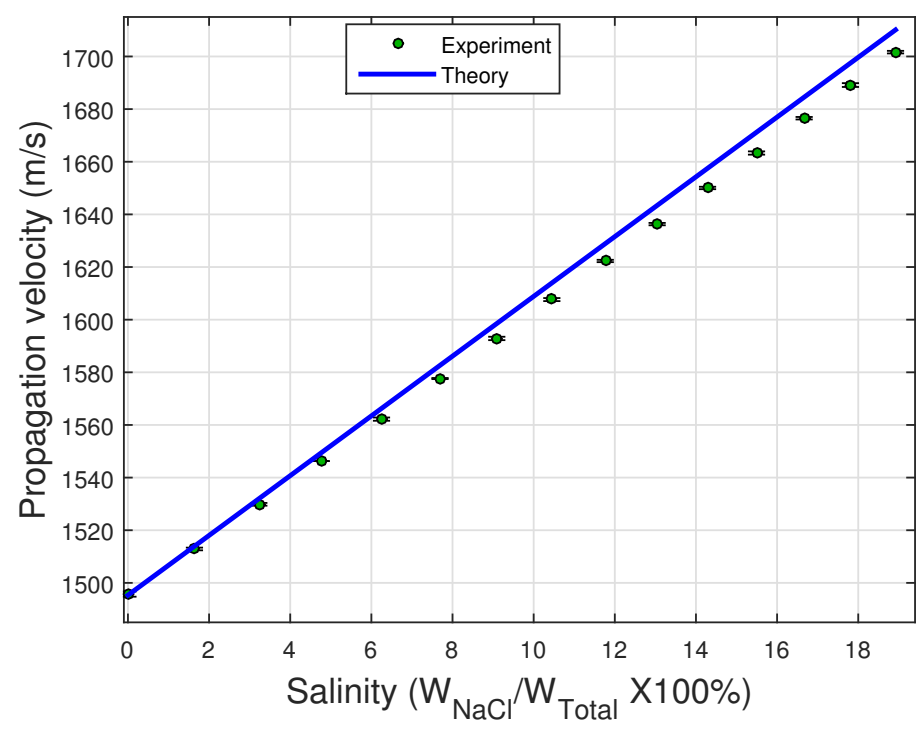

Figure 4. Propagation velocity for saline solutions at $25^{\circ} \mathrm{C}$ as a function of salt concentration by weight compared to the theoretical model obtained from [35].

Figure 5a shows the propagation velocity in the emulsion as a function of the acquisition time. The acquisition time was $160 \mathrm{~min}$, beginning when the rest time ends (40 s). The results for three concentrations $(\phi=0.12,0.21,0.29)$ and for both the static and moving cases are shown. In all these cases, a reduction in propagation velocity is observed in the first 10-20 min. From the minimum value observed at the beginning of the curve, the velocity rises; at the end of the acquisition time, there is an increase of $0.3 \%$ and $0.7 \%$ for the static and moving cases, respectively. This increase in velocity is relatively small and can be explained by physical changes in the emulsion, mainly coalescence. The behavior is similar in all three concentrations. However, it is evident that a steady state value was not reached at the end of the acquisition time.

Figure $5 \mathrm{~b}$ shows the propagation velocity as a function of the acquisition time for the transducer placed at the top (close to the free surface of the sample) and at the bottom of the beaker, and for static and moving cases. Measurements at the top and bottom of 
static and moving samples were performed using a water volume fraction of 0.29 . The results show that, in the static case, the propagation velocity curves are almost identical for both sensor positions, whereas in the case of the emulsion under stirring, the curves were different. When the sensor is located at the bottom of the container, the propagation velocity is slightly higher throughout the experiment. Furthermore, after the minimum value presented at the beginning of the curve, the propagation velocity value increases at a higher rate than in the other three cases and presents less dispersion than in the static case. When the sensor is located at the top, the curve is similar to that observed in the static case. The increase in velocity after the minimum value is linear and presents less dispersion.

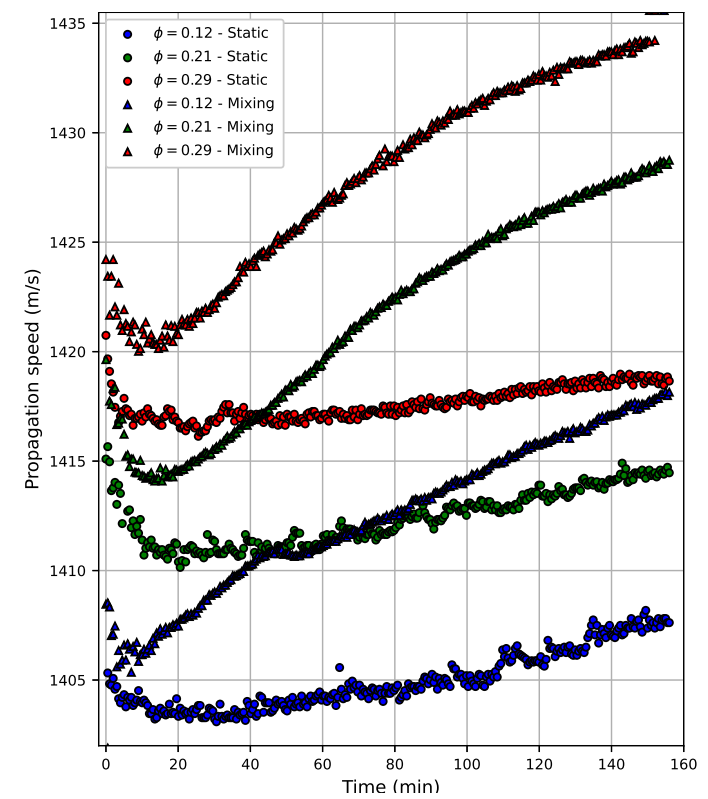

(a)

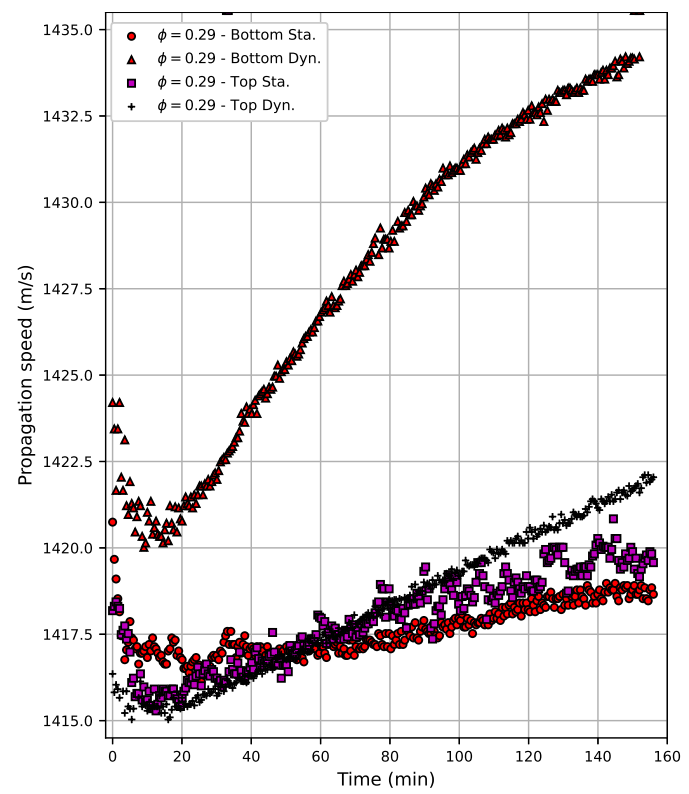

(b)

Figure 5. Propagation velocity as a function of acquisition time at $25.0^{\circ} \mathrm{C}$ : (a) comparison of static and in motion cases and (b) measurements at top (near free surface) and bottom of the sample for $\phi=0.29$.

The propagation velocity increased at a higher rate in the moving emulsion with the sensor located at the bottom of the container, when compared to the moving emulsion with the sensor located at the top. This happened due to the increase in coalescence. The movement of the emulsion increases the probability of the water droplets to collide and merge, generating larger water droplets that move towards the bottom of the container under the action of gravity [36].

Figure 6 shows the propagation velocity in the emulsions as a function of water volume fraction ( $\phi=0.12,0.21$ and 0.29$)$ at three time instants $(t=2,80,160 \mathrm{~min})$ for both static and moving cases. The theoretical propagation velocity according to the Urick mixture model is shown as a solid line. The results for the static case are closer to the theoretical behavior than the moving case for all instants of time. With the mixer turned on (in the motion case), an almost constant velocity difference (offset value) that depends on time is observed. At the first time instant $(2 \mathrm{~min})$, the velocity values have a maximum difference of just $0.3 \%$ with respect to the theoretical values. Thus, to ensure that the emulsion concentration does not change due to coalescence, the characterization could be carried out two minutes after the emulsification process and the rest time.

Figure 7a shows the average of the 30 measurements taken during the first $110 \mathrm{~s}$ (after emulsification and resting steps) at three temperatures for the static case. The measurement results were compared with their respective theoretical curves obtained with Urick's model (solid lines). The results are in agreement with the theoretical values, showing the same almost linear trend of the model and allowing a clear differentiation of measurements at the three temperatures. The differences in the mean values of the propagation velocity 
between static and in-motion emulsions (see Figure $7 \mathrm{~b}$ ) at the same concentration are less than $0.16 \%$. These results show that the difference in the propagation velocity of static and moving emulsions is small when the characterization is made immediately after the emulsification and resting (40 s) processes ends. The propagation velocities measured at $20^{\circ} \mathrm{C}$ and $25^{\circ} \mathrm{C}$ (red square and blue triangle data) in the static emulsions are similar to the experimental results of propagation velocity in water-in-crude-oil emulsions shown in [28], in which the sensor uses a single transducer, a set of steel bars as a reflector and its volume is ten times greater in comparison to the prototype proposed herein. The same base crude oil used to produce the samples here were used in [28], but there the experiments were carried out at $22{ }^{\circ} \mathrm{C}$ with water content from $\phi=0$ to $\phi=0.37$, with an ultrasonic multiple-backscattering sensor.

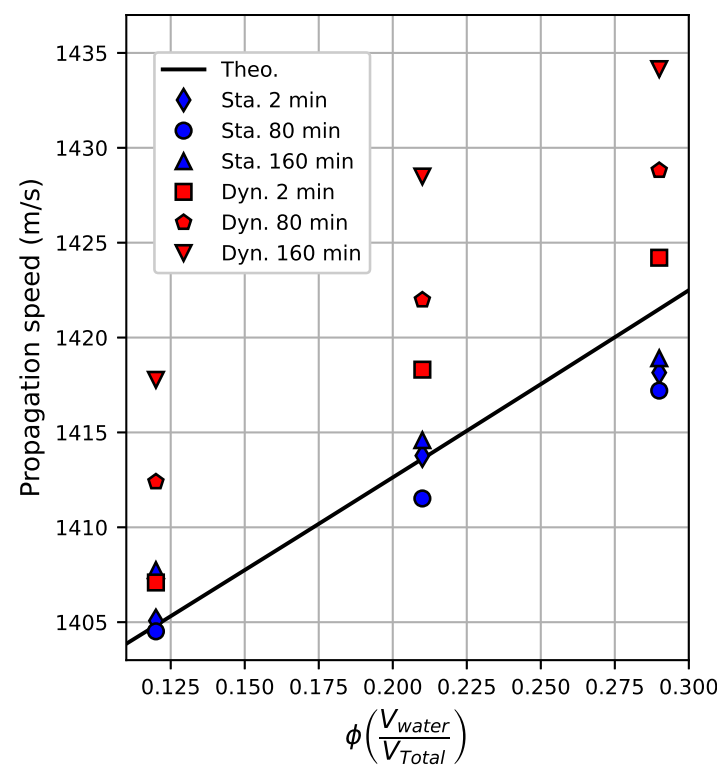

Figure 6. Urick model comparison at $T=25^{\circ} \mathrm{C}$. Considering the propagation velocity, the maximum absolute deviation from the mean is $8.1 \frac{\mathrm{m}}{\mathrm{s}}\left(\operatorname{dev}_{\max }=0.6 \%\right)$ at $\phi=0.29$.

(a)

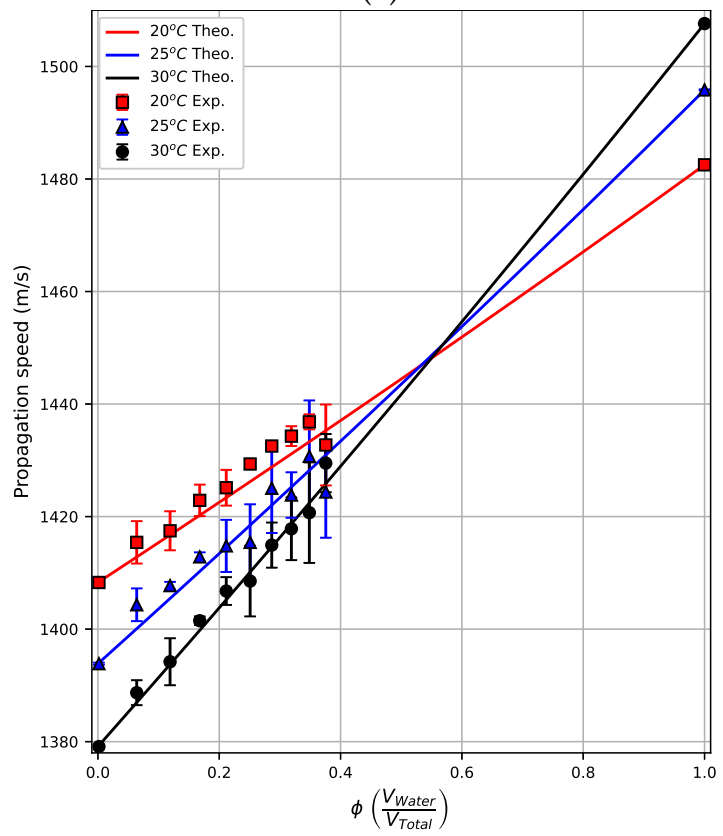

(b)

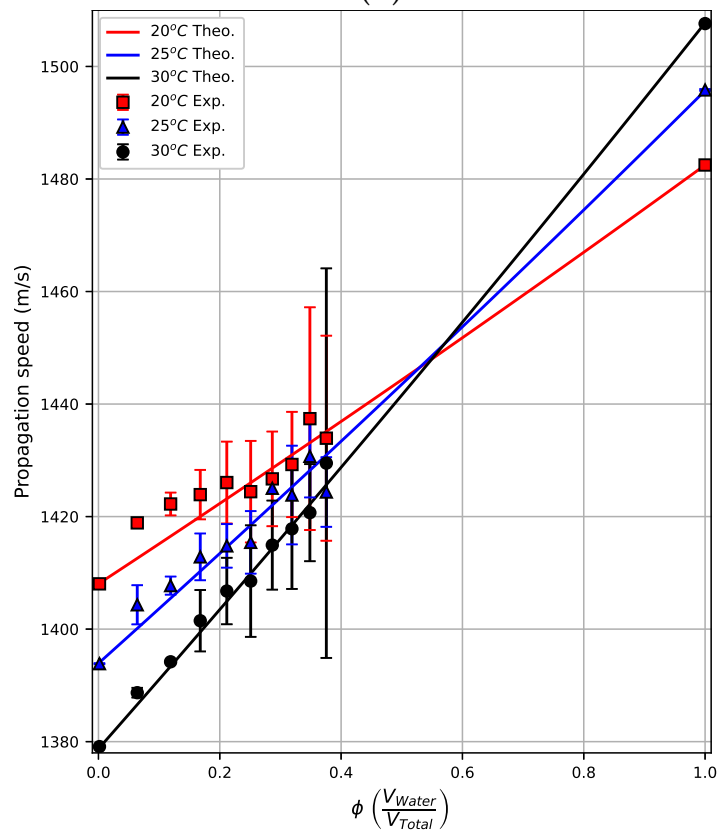

Figure 7. (a) Mixer turn off $\left(d e v_{\max }=1.3 \%\right)$ and $(\mathbf{b})$ Mixer turn on $\left(d e v_{\max }=4.8 \%\right)$. 
The results from the emulsion in motion showed greater standard deviations at the highest water concentrations. This behavior shows greater instability of the physical properties of the emulsion at these concentrations. Tests carried out with the mixer turned on and with a blade tip speed greater than $1 \mathrm{~m} / \mathrm{s}$ showed widely dispersed results (not shown here) for all concentrations.

In the case of moving samples, the propagation velocity variations in the emulsions for $\phi>0.25$ may be a consequence of the formation of water droplets with sizes close to wavelength, increasing the acoustic diffraction. This effect can also increase when temperature or flow velocity increases because the organic gases dissolved in the oil can form bubbles that can affect the wave propagation.

In Figure 5a, the tested emulsions were prepared from mixtures of pure oil and water. In Figure $7 \mathrm{a}, \mathrm{b}$, the tested samples were prepared by adding water to the emulsion previously used, obtaining new concentrations. In Figure 5a, the propagation velocity values for $\phi=0.12,0.21$ and 0.29 obtained during the first $5 \mathrm{~min}$ at $25{ }^{\circ} \mathrm{C}$ are similar to those obtained for the same concentrations at $25^{\circ} \mathrm{C}$ in Figure 7 (blue triangles). Although the method of emulsion preparation was different from the results presented in Figures $5 \mathrm{a}$ and 7 , close values were obtained, suggesting that the droplet behavior is similar regardless of the method of emulsion preparation.

\section{Conclusions}

A feasibility study of the real-time estimation by ultrasound of the water content in oil in static and moving emulsions, taking into account the temperature effect, was presented. The methodology employed made it possible to measure the emulsion properties under the proposed conditions. The presented technique is a variation of acoustic characterization of materials, widely used in liquids and solids. It allows the measurement of water content emulsified with crude oil, showing results close to those described by the Urick model. Water concentration measurements in stirring emulsions show a greater standard deviation compared to emulsions at rest. However, the mean velocity values are similar for both static and moving emulsions. Although this technique is not useful to obtain the correct instantaneous values of water concentration before $3 \mathrm{~min}$ after emulsification, an average of 30 measurements or more, obtained over that initial stage, could allow the measurement. The measuring accuracy of samples at different temperatures can be significantly increased in static emulsions. The depth positioning of the probe is relevant in the case of movement.

The determination of the water concentration in the emulsions within small time intervals (minutes) in relation to other methods (hours) indicates that the acoustic technique proposed herein could be useful for monitoring water in crude oil emulsions in real-time, before and after the induced coalescence processes that occur in the petrochemical industry.

Author Contributions: C.A.B.R. manufactured the sensor; C.A.B.R. and A.L.D. carried out the experiments; C.A.B.R., E.E.F. and F.B. researched the data processing; All the authors participated in the results analysis and discussion; C.A.B.R., E.E.F. and F.B. wrote the manuscript, organized and supervised the research. M.S.G.T. and L.O.V.P. are responsible for the funding acquisition. All authors have read and agreed to the published version of the manuscript.

Funding: This research was funded by Petrobras/ANP (grant 5850.0108871.18.9), CAPES/PROAPGrant 817.757/38.860 and CNPq (MSG Tsuzuki was partially supported by grant 311.195/2019-9). EE Franco had financial support from the Universidad Autónoma de Occidente (Colombia) by grant 19INTER-306.

Conflicts of Interest: The authors declare no conflict of interest.

\section{References}

1. Shah, A.; Fishwick, R.; Wood, J.; Leeke, G.; Rigby, S.; Greaves, M. A review of novel techniques for heavy oil and bitumen extraction and upgrading. Energy Environ. Sci. 2010, 3, 700-714. [CrossRef]

2. Thomas, J.E. Fundamentos de Engenharia de Petróleo; Interciência: Rio de Janeiro, Brazil 2001.

3. Rio, E.; Biance, A.L. Thermodynamic and mechanical timescales involved in foam film rupture and liquid foam coalescence. ChemPhysChem 2014, 15, 3692-3707. [CrossRef] 
4. Critello, D.C.; Pullano, S.A.; Gallo, G.; Matula, T.J.; Fiorillo, A.S. Low frequency ultrasound as a potentially viable foaming option for pathological veins. Colloids Surf. A Physicochem. Eng. Asp. 2020, 599, 124919. [CrossRef]

5. Morgan, V.G.; Sad, C.; Constantino, A.F.; Azeredo, R.B.; Lacerda, V.; Castro, E.V.; Barbosa, L.L. Droplet size distribution in water-crude oil emulsions by low-field NMR. J. Braz. Chem. Soc. 2019, 30, 1587-1598. [CrossRef]

6. Raigan, K. Ultrasonic Techniques for Characterizations of Oils and Their Emulsions and Monitoring Oil Layer Depth of Spill Emulsions and Monitoring Oil Layer Depth of Spill. Ph.D. Thesis, The University of Western Ontario, London, ON, Canada, 2020.

7. Jadoon, S.; Malik, A.; Amin, A.A. Separation of Sediment Contents and Water from Crude Oil of Khurmala and Guwayer Oil Fields in Kurdistan Region by using Centrifuge Method. Int. J. Adv. Eng. Res. Sci. 2017, 4, 2919-2922. [CrossRef]

8. Ivanova, P.G.; Aneva, Z.V. Assessment and assurance of quality in water measurement by coulometric Karl Fischer titration of petroleum products. Accredit. Qual. Assur. 2006, 10, 543-549. [CrossRef]

9. Perez, N.; Blasina, F.; Buiochi, F.; Duran, A.; Adamowski, J. Evaluation of a multiple scattering sensor for water-in-oil emulsion monitoring. In Proceedings of the Meetings on Acoustics ICU. Acoustical Society of America, San Diego, CA, USA, 2-6 December 2019; Volume 38, p. 055007.

10. Wang, K.; Liu, Z.; Liu, G.; Yi, L.; Yang, K.; Peng, S.; Chen, M. Vibration sensor approaches for the monitoring of sand production in Bohai bay. Shock Vib. 2015, 2015, 591780.

11. Runrun, H.; Runyang, M.; Chenghui, W.; Jing, H. Ultrasonic shear-wave reflectometry applied to monitor the dynamic viscosity of reheated edible oil. J. Food Process. Eng. 2020, 43, e13402. [CrossRef]

12. Franco, E.E.; Adamowski, J.C.; Higuti, R.T.; Buiochi, F. Viscosity measurement of Newtonian liquids using the complex reflection coefficient. IEEE Trans. Ultrason. Ferroelectr. Freq. Control 2008, 55, 2247-2253. [CrossRef]

13. Kazys, R.; Voleisis, A.; Sliteris, R. Investigation of the Acoustic Properties of Viscosity Standards. Arch. Acoust. 2016, 41, 55-58. [CrossRef]

14. Alig, I.; Lellinger, D.; Sulimma, J.; Tadjbakhsch, S. Ultrasonic shear wave reflection method for measurements of the viscoelastic properties of polymer films. Rev. Sci. Instrum. 1997, 68, 1536-1542. [CrossRef]

15. Wang, X.; Subramaniam, K.V.; Lin, F. Ultrasonic measurement of viscoelastic shear modulus development in hydrating cement paste. Ultrasonics 2010, 50, 726-738. [CrossRef] [PubMed]

16. Meng, G.; Jaworski, A.J.; White, N.M. Composition measurements of crude oil and process water emulsions using thick-film ultrasonic transducers. Chem. Eng. Process. Process. Intensif. 2006, 45, 383-391. [CrossRef]

17. Lu, Z.Q.; Yang, X.; Zhao, K.; Wei, J.X.; Jin, W.J.; Jiang, C.; Zhao, L.J. Non-contact Measurement of the Water Content in Crude Oil with All-Optical Detection. Energy Fuels 2015, 29, 2919-2922. [CrossRef]

18. Chillara, V.K.; Sturtevant, B.T.; Pantea, C.; Sinha, D.N. Ultrasonic sensing for noninvasive characterization of oil-water-gas flow in a pipe. AIP Conf. Proc. 2017, 1806, 090014.

19. Higuti, R.T.; Bacaneli, E.; Furukawa, C.M.; Adamowski, J.C. Ultrasonic characterization of emulsions: Milk and water in oil. In Proceedings of the 1999 IEEE Ultrasonics Symposium, Caesars Tahoe, NV, USA, 17-20 October 1999; International Symposium (Cat. No. 99CH37027); IEEE: Piscataway, NJ, USA, 1999; Volume 1, pp. 779-782.

20. McClements, D.J. Ultrasonic characterizations of emulsions and suspensions. Adv. Colloid Interface Sci. 1997, 37, 33-72. [CrossRef]

21. Stolojanu, V.; Prakash, A. Cgaracterization of slurry systems by ultrasonic techniques. Chem. Eng. J. 2001, 84, 215-222. [CrossRef]

22. Franco, E.E.; Adamowski, J.C.; Buiochi, F. Ultrasonic sensor for the presence of oily contaminants in water. Dyna 2012, 79, 4-9.

23. Maia Filho, D.C.; Ramalho, J.B.; Spinelli, L.S.; Lucas, E.F. Aging of water-in-crude oil emulsions: Effect on water content, droplet size distribution, dynamic viscosity and stability. Colloids Surf. A Physicochem. Eng. Asp. 2012, 396, 208-212. [CrossRef]

24. Richter, A.; Voigt, T.; Ripperger, S. Ultrasonic attenuation spectroscopy of emulsions with droplet sizes greater than 10 microm. J. Colloid Interface Sci. 2007, 315, 482-492. [CrossRef] [PubMed]

25. Su, M.; Cai, X.; Xue, M.; Dong, L.; Xu, F. Particle sizing in dense two-phase droplet systems by ultrasonic attenuation and velocity spectra. Sci. China Ser. E Technol. Sci. 2009, 52, 1502-1510. [CrossRef]

26. Dukhin, A.S.; Goetz, P.J. (Eds.) Characterization of Liquids, Nano- and Microparticulates, and Porous Bodies Using Ultrasound, 2nd ed.; Studies in Interface Science 24; Elsevier: Amsterdam, The Netherlands, 2010.

27. Silva, C.A.; Saraiva, S.V.; Bonetti, D.; Higuti, R.T.; Cunha, R.L.; Pereira, L.O.; Silva, F.V.; Fileti, A.M. Application of acoustic models for polydisperse emulsion characterization using ultrasonic spectroscopy in the long wavelength regime. Colloids Surf. A Physicochem. Eng. Asp. 2020, 602, 125062. [CrossRef]

28. Durán, A.L.; Franco, E.E.; Reyna, C.A.; Pérez, N.; Tsuzuki, M.S.; Buiochi, F. Water Content Monitoring in Water-in-Crude-Oil Emulsions Using an Ultrasonic Multiple-Backscattering Sensor. Sensors 2021, 21, 5088. [CrossRef] [PubMed]

29. Urick, R.J. A Sound Velocity Method for Determining the Compressibility of Finely Divided Substances. J. Appl. Phys. 1947, 18, 983-987. [CrossRef]

30. Hubbard, J.C.; Loomis, A. CXXII. The velocity of sound in liquids at high frequencies by the sonic interferometer. Lond. Edinb. Dublin Philos. Mag. J. Sci. 1928, 5, 1177-1190. [CrossRef]

31. Adamowski, J.C.; Buiochi, F.; Tsuzuki, M.S.G.; Pérez, N.; Camerini, C.S.; Patusco, C. Ultrasonic measurement of micrometric wall-thickness loss due to corrosion inside pipes. In Proceedings of the IEEE International Ultrasonics Symposium (IUS), Prague, Czech Republic, 21-25 July 2013; pp. 1881-1884. 
32. Takimoto, R.Y.; Matuda, M.; Lavras, T.; Adamoswki, J.; Pires, G.; Peres, N.; Ueda, E.; Tsuzuki, M.S.G. An echo analysis method for the ultrasonic measurement of micrometric wall-thickness loss inside pipes. In Proceedings of the 2018 13th IEEE International Conference on Industry Applications, São Paulo, Brazil, 12-14 November 2018; pp. 999-1003.

33. Duran, A.L.; Sato, A.K.; Silva, A.M., Jr.; Franco, E.E.; Buiochi, F.; Martins, T.C.; Adamowski, J.C.; Tsuzuki, M.S.G. GPU Accelerated Acoustic Field Determination for a Continuously Excited Circular Ultrasonic Transducer. In Proceedings of the 21st IFAC World Congress, Berlin, Germany, 11-17 July 2020; pp. 10480-10484.

34. Takimoto, R.Y.; Matuda, M.Y.; Oliveira, T.F.; Adamowski, J.C.; Sato, A.K.; Martins, T.C.; Tsuzuki, M.S.G. Comparison of optical and ultrasonic methods for quantification of underwater gas leaks. In Proceedings of the 21st IFAC World Congress, Berlin, Germany, 11-17 July 2020; Volume 53, pp. 16721-16726.

35. Kleis, S.; Sanchez, L. Dependence of speed of sound on salinity and temperature in concentrated NaCl solutions. Sol. Energy 1990, 45, 201-206. [CrossRef]

36. Alshaafi, E. Ultrasonic Techniques for Characterization of Oil-Water Emulsion and Monitoring of Interface in Separation Vessels and Monitoring of Interface in Separation Vessels. Master's Thesis, The University of Western Ontario, London, ON, Canada, 2017. 